\title{
Identidad docente y políticas de accountability: el caso de Chile ${ }^{1}$
}

\author{
Educational identity and policies of accountability: the case of Chile
}

\author{
Claudia Carrasco Aguilara, Antonio Luzón ${ }^{b}$, Verónica López ${ }^{c}$ \\ ${ }^{a}$ Universidad de Playa Ancha, Chile. \\ claudia.carrasco@upla.cl \\ ${ }^{\text {b}}$ Universidad de Granada, España. \\ aluzon@ugr.es \\ ${ }^{\mathrm{c}}$ Centro de Investigación para la Educación Inclusiva. \\ Pontificia Universidad Católica de Valparaíso, Chile. \\ veronica.lopez@pucv.cl
}

\section{RESUMEN}

Las políticas de rendición de cuentas en Chile se sustentan sobre un sistema de medición de calidad de la educación que trae consigo pruebas estandarizadas con altas consecuencias, y diferentes sistemas de amenaza, castigo y seducciones para las escuelas que no mejoren sus resultados académicos. En este contexto, la identidad del profesorado se ve desafiada. Este estudio analizó la identidad del profesorado que trabaja en sistema municipal chileno en el contexto de políticas de accountability en este sector. Se realizaron 22 entrevistas focalizadas y 4 grupos focales a docentes y otros actores educativos de cuatro centros educativos cuyo índice de vulnerabilidad socioeducativa (IVE) era superior a 75\%. Los resultados del análisis de contenido indican una estandarización del trabajo docente, lo que trae como consecuencia tanto una tecnificación de su identidad, como formas de responder por medio de la vocación y compromiso profesional, a pesar de un descrédito de la profesión. Esta percepción es compartida por el estudiantado y sus familias, quienes confirman la percepción del profesorado de un bajo reconocimiento social.

Palabras claves: estandarización, vocación, compromiso, profesorado, Chile.

\begin{abstract}
Accountability policies in Chile are based on a quality education measurement system that includes standardized testing with high consequences, and different threat, punishment and seduction systems for schools that do not improve their academic results. In this context, the identity of teachers is defied. This study sought to analyze the identity of teachers working in the chilean municipal system in the context of accountability policies in this sector. We conducted 22 focused interviews and 4 focus groups with teachers and other educational actors from four educational centers whose socio-educational vulnerability index (IVE) was higher than 75\%. The results of the content analysis indicate a standardization of the teaching work, which brings as a consequence both a technification of their identity as well as ways of responding through vocation and professional commitment, despite a discredit of the profession. This perception is shared by the students and their families, who confirm teacher's perception of low social recognition
\end{abstract}

Key words: standardization, vocation, commitment, teachers, Chile.

FONDECYT N ${ }^{\circ} 11190339$ Trayectorias docentes: Análisis en el marco del Sistema de Desarrollo Profesional Docente, FONDECYT N 1191267 La inclusión excluyente: prácticas de exclusión y segregación en escuelas chilenas, PIA Conicyt CIE 160009. 


\section{NUEVA GESTIÓN PÚBLICA Y RENDICIÓN DE CUENTAS: EL CASO DE CHILE}

Diferentes macropolíticas supranacionales impulsadas por organismos de articulación y alianza inter-países como la Organización para la Cooperación y el Desarrollo Económicos (OCDE) y la Organización de las Naciones Unidas para la Educación, la Ciencia y la Cultura (Unesco), en la actualidad influyen de forma significativa -aunque no exclusiva- el desarrollo profesional docente entre otras políticas y reformas educativas (Luzón y Torres, 2013). Así es como muchos debates educativos de países que componen la OCDE guardan relación con la permeabilidad de los sistemas escolares a las lógicas de la mercantilización, instalando mecanismos orientados hacia la privatización y rendición de cuentas. Desde el enfoque de la OCDE, estos mecanismos tienen su origen en la década de 1970, debido a que diferentes modelos de educación comprehensiva y Estados de bienestar comienzan a mostrar importantes crisis con impacto en el diseño e implementación de las políticas de desarrollo. La consecuencia de esto fue el cuestionamiento de la centralidad del Estado, el que es cuestionado en cuanto a la legitimidad de su rol de garante y administrador de la educación pública (Villalobos y Quaresma, 2015).

De este modo paulatinamente se han ido instalando sistemas de rendición de cuentas (accountability) que asumen que las escuelas son responsables de la oferta que proveen (Falabella y De la Vega, 2016). Los sistemas de rendición de cuentas tienen su origen en el Programa Internacional para la Evaluación de los Estudiantes (PISA) impulsado por la OCDE el año 2000, así como en otros organismos internacionales como el Banco Mundial y Unesco (Beltrán, 2016; Kallo, 2009; Parcerisa y Verger, 2016). Dependiendo de a quien se dirige la rendición de cuentas y las consecuencias de éstas, la literatura ha clasificado el accountability como interno, externo o público, de altas consecuencias, performativo, de tipo político, legal, burocrático, profesional, basado en un modelo de mercado, participativo o social, soft o reflexivo, entre otros (De la Vega, 2015; Dussaillant y Guzmán, 2014; McMeekin, 2006; Parcerisa y Verger, 2016).

Si bien en algunos países existe más bien una connotación negativa sobre el accountability, éste se ha desarrollado en el marco de diversas experiencias democráticas, propuestas teóricas y políticas avanzadas, y se ha basado en diferentes presupuestos políticos, éticos, epistemológicos y educativos, lo que sumado a su extensa clasificación no permite establecer una definición homogénea del concepto (Alfonso, 2016; Dutercq, 2016; Parcerisa y Verger, 2016). De todos modos, incluso en aquellos contextos en los que la rendición de cuentas tuvo en sus comienzos el objetivo de aumentar el control democrático y ciudadano de la educación, en los últimos años ha tomado un camino diferente, adquiriendo un carácter más bien gerencial (Parcerisa y Verger, 2016). En los sistemas de rendición de cuentas performativo, muchos centros educativos generan estrategias que les permiten ser cada vez más eficientes en la administración de los tiempos y resultados, construyendo identidades docentes más cercanas a la imagen del gerente de empresa que a la del profesor que se prepara para el currículum. El sistema de rendición de cuentas performativo -denominado también en la literatura como rendición de cuentas fuerte (strong accountability) y rendición de cuentas con altas consecuencias (high stake accountability)- requiere de un enfoque educativo gerencial para poder desarrollarse, por lo que, aunque no son exactamente lo mismo, muchos autores se refieren a este modelo como una rendición de cuentas gerencial (Lima, 2016; Parcerisa y Verger, 2016). Sin embargo, el enfoque gerencial de la rendición de cuentas no es exclusivo de modelos más duros o 
con altas consecuencias, ya que se trata más bien de una tendencia que paulatinamente y desde la implementación de diferentes reformas educativas impulsadas por la OCDE, ha ido creciendo en los países cuyos resultados en pruebas estandarizadas como PISA han presentado disminuciones o resultados desfavorables. En muchos países estas iniciativas se presentan como consecuencia de la instalación de políticas sociales neoliberales (Verger y Normand, 2015) y han sido denominadas pedagogías basadas en la gestión (Giroux, 1992) o enfoque de la nueva gestión pública [NGP] (New Public Managment) (Sisto, 2011; Sisto y Fardella, 2011; Verger y Normand, 2015; Verger, Zancajo y Fontdevila, 2016).

La NGP es todo un programa de reformas del sector público, cuya principal característica en educación es el traslado de conocimientos e instrumentos de la gestión empresarial, fragmentando los servicios públicos en unidades independientes a través de la autonomía y búsqueda de resultados tangibles. Estas reformas no aspiran a la anulación del Estado, sino que se espera que éste fortalezca su rol de regulador, evaluador y distribuidor de incentivos a los proveedores autónomos de dichos servicios (Verger y Normand, 2015). Lo más característico de un sistema de rendición de cuentas performativo basado en el modelo de la NGP, son las altas consecuencias de las evaluaciones, las que son definidas como de alto riesgo (Brooke, 2016; Parcerisa y Verger, 2016) y se caracterizan por ser estandarizadas y permitir la comparación de colegios (Lima, 2016). Estas reformas ponen el acento en los aprendizajes del estudiantado y en el rendimiento de la escuela, bajo mecanismos de presión que dificultan la innovación del centro educativo como comunidad profesional de aprendizaje (Bolívar, 2010).

En Chile, el papel del profesorado ha mutado en los últimos 30 años debido a las diferentes transformaciones sociopolíticas tendientes a la instalación de un modelo educativo de mercantilización (Biscarra, Giaconi, y Assáel, 2015; Cornejo et al., 2015; Insunza, Assáel y Scherping, 2011). Así es como Chile posee un enfoque de rendición de cuentas por desempeño escolar (Falabella y De la Vega, 2016), que ha sido acompañado de mecanismos de mercado a escala nacional y de manera universal, convirtiéndose en el enfoque absoluto del NGP más antiguo en el mundo (Verger et al., 2016). Estas reformas se dan en un escenario de altos niveles de desigualdad y exclusión (Cavieres, 2014), con un sistema educativo que ha dejado la educación pública asociada a la pobreza. Este escenario, incluso ha sido reconocido por la propia OCDE (2016), lo que es señalado como un nudo crítico importante que el país debe superar.

Pese a los esfuerzos por fortalecer el modelo de la NGP y el accountability en Chile, hasta ahora no existe suficiente evidencia científica para demostrar que el enfoque de rendición de cuentas tenga un impacto positivo sobre la calidad educativa (Alves et al., 2015). En cambio, la literatura nacional ha mostrado crecientemente consecuencias de estas reformas en términos de desgaste docente y desigualdades sociales (Assáel y Pavez, 2008; Bellei, 2013; Elacqua y Santos, 2013; Falabella, 2015; Flórez, 2015). En el marco internacional, uno de los ejemplos más connotados en esta materia ocurrió en Estados Unidos bajo la reforma educativa que implementó George Bush y que fue apaciguada por Barak Obama, llamada "Que ningún niño quede atrás" (No child left behind [NCLB]). El programa norteamericano consistió en un profundo sistema de privatización y énfasis en resultados que convirtió a las escuelas en organizaciones de gestión a través de pruebas estandarizadas con altas consecuencias (high-stakes testing) y sistemas de financiamiento a la demanda (voucher) (Hursh, 2008). Popkewitz (2009) se refiere a esta política como el mejor ejemplo para describir la forma en que el neoliberalismo confía en el mercado para las decisiones 
educativas. La política del NCLB no abordó las inequidades sociales y estructurales que producen resultados dispares entre los centros educativos (Ravitch, 2010), y generó un ambiente punitivo de política educativa a través de la competencia entre distritos y escuelas junto con la instalación de un sistema de sanciones (Heilig y Darling-Hammond, 2008; Schildkamp y Ehren, 2013; Wayman, Spikes y Volonnino, 2013). En Chile, al analizar el escenario educativo que derivan de políticas como la Ley de Subvención Escolar Preferencial (Ley SEP) y la Política de convivencia escolar, diferentes autores llegan a conclusiones similares, describiendo en nuestro país un ambiente de política punitiva (Carrasco, Ascorra, López y Álvarez, 2018; López, 2014; Rojas y Leyton, 2014). De todos modos, autores como Falabella (2018) sostienen que las políticas de rendición de cuentas no son sólo punitivas, ya que resultan al mismo tiempo seductoras. Si bien estas reformas incorporan inspecciones y sanciones, poseen cierta elasticidad y ambigüedad, lo que se evidencia en los principios éticos dobles de derecho y libertad, regulaciones y diversidad; y público y privado (Parcerisa y Falabella, 2017). Las prácticas en torno a estos principios podrían cuestionar la existencia absoluta de un ambiente punitivo, complejizando aún más el fenómeno.

Actualmente, resulta difícil pensar en una política educativa dirigida a la calidad sin construir estándares deseables para avanzar en la mejora educativa. Las críticas al modelo de la NGP y sus formas de accountability no pretenden oponerse a cualquier forma de control sobre las escuelas y el profesorado, sino que se trata de establecer dispositivos para garantizar que las escuelas mejoren con recursos oportunos y evitar que el estándar se convierta en una estandarización (Bolívar, 2005). En el enfoque de NGP esta estandarización exige rendición de cuentas con el fin de generar auditorías públicas que promuevan el rol consumidor de las familias en desmedro de un rol colaborador (Verger y Normand, 2015; Verger, Zancajo y Fontdevila, 2016). En Chile, la educación tiene un modelo de libertad de elección del centro, así como de competencia entre éstos (Mediavilla, Zancajo, Verger y Bonal, 2013).

La idea de que las familias elijan el centro educativo se basa en la teoría de la elección pública, que parte de la premisa de que las personas buscan la maximización de sus funciones de utilidad. Esta teoría busca introducir mecanismos de mercado en los servicios públicos, como la desregulación, la competencia entre proveedores, la introducción de lógicas de gestión basadas en resultados y la libre elección de servicios por parte de las personas (Verger et. al, 2016). El sistema educativo chileno “(...) se ha convertido en el mayor cuasi-mercado de la región latinoamericana" (Mediavilla et. al, 2013, p. 3). Así, Chile se convierte en un caso excepcional. El modelo de cuasi-mercado chileno ha sido utilizado como referente de calidad y ejemplo de éxito desde los asesores del Banco Mundial y de otros organismos internacionales (Almonacid, 2001), pese a que sus consecuencias han sido devastadoras desde una perspectiva de derecho (Joiko, 2012). Es por esto por lo que muchos estudios sobre las implicancias del accountability consideran a Chile como un caso de estudio (Almonacid, Luzón y Torres, 2009; Parcerisa y Falabella, 2017; Verger et al., 2016).

\section{IDENTIDAD DOCENTE: ENTRE POLÍTICAS Y VOCACIÓN}

La figura del profesorado en el sistema educacional se construye y modifica a partir de cómo las políticas definen su trabajo, impactando tanto en sus prácticas como en las relaciones sociales y en su identidad (Biscarra et al., 2015; Cornejo y Reyes, 2008; Galaz, 2015; Reyes, Varas y Zelaya, 2015). En las políticas gerenciales de la educación el profesorado 
suele quedar relegado a un rol ejecutor de las mismas (Bazán y González, 2007; Hargreaves, 2003; Fardella y Sisto, 2015) y muchas veces es reducido a la didáctica y al correcto ejercicio de la transmisión de contenidos. Aunque en varias ocasiones se puede apreciar la reflexión sobre el nivel práctico de la acción docente, las políticas de NGP dificultan que el profesorado cuestione las implicancias de éstas (Hypolito, Pizzi y Vieira, 2009).

El estudio llevado a cabo por Etcheberrigaray, Lagos, Cornejo, Albornoz, y Fernández (2017) concluye que las transformaciones legales en la educación chilena consolidan el discurso empresarial y buscan transformar el rol docente hacia tareas de tipo técnicas, estandarizadas y sometidas de forma permanente a evaluación. Así es como en la actualidad se han desarrollado diferentes dispositivos legales y de perfeccionamiento de apoyo al estatuto y a la carrera docente, pero sin reconocerle al profesorado suficiente autonomía para su ejercicio profesional (Sisto y Fardella, 2011), lo que terminará por intensificar y deteriorar aún más sus condiciones laborales y ambientes de trabajo (Cavieres y Apple, 2016; Reyes, Cornejo, Arévalo y Sánchez, 2010).

Sin embargo, la identidad docente no es un pálido reflejo de lo que las políticas esperan. Si bien las políticas educativas operan como un dispositivo subjetivante (Fardella y Sisto, 2015; Sisto, 2012), existen estudios que dan cuenta de diversos encuentros y desencuentros que se producen entre la identidad promovida y la identidad construida por el profesorado (Galaz, 2011), así como experiencias en las cuales se avanza identitariamente hacia una reconfiguración política del trabajo docente (Reyes, et al., 2010). Esto ha sido reportado como formas de resistencia a la reproducción de los discursos oficiales de las políticas de fortalecimientos de la profesión docente, y el componente colectivo aparece como central en el análisis de las posibilidades de acción productiva de una identidad que resista los mecanismos de desprofesionalización (Pino, Oyarzún y Salinas, 2016; Fardella, 2013; Fardella y Sisto, 2015).

Debido a lo anterior, la identidad docente no puede ser estudiada solo como un efecto de las políticas, lo que se suma al hecho de que es imposible hablar de una sola identidad magisterial (Ávalos y Sotomayor, 2012; Núñez, 2004). Si bien la identidad es un constructo relativo al contexto sociohistórico en el que se produce, es al mismo tiempo un dilema entre la singularidad de uno mismo y la similitud con los otros (Íñiguez, 2001). Es por esto por lo que, en determinados contextos educativos, el tejido de las relaciones sociales vividas por el profesorado en su propia comunidad también es generador de identidad, sobre todo en un contexto social en el que pareciera ser que todos pueden emitir juicios y opinar sobre el profesorado y su trabajo (González, 2002).

En diferentes países se ha ido creando una imagen cultural de descrédito de la profesión docente, la que surge desde las familias del estudiantado, las condiciones laborales y el escaso reconocimiento de las autoridades ministeriales o gubernamentales (Fernández, 2001; Gavilán, 1999). Esta imagen del profesorado sería diferente en contextos socioeducativos que cuentan con modelos de confianza, bajo los cuales no tiene cabida el accountability (Dussaillant y Guzmán, 2014). En Chile, el juicio social negativo que muchas veces existe sobre el profesorado, y especialmente, sobre el profesorado que trabaja en sectores municipales y de pobreza, se construiría sobre la base de los indicadores de resultados medidos fundamentalmente en pruebas estandarizadas como el Sistema de Medición de la Calidad Educativa (SIMCE) (Guerrero, 2017).

Autores como Esteve (2009) plantean que hubo una época en que el profesorado era reconocido como un grupo con estatus social y cultural elevado, ya que las cualidades que 
se valoraban entonces eran fundamentalmente la abnegación y la vocación, estableciendo un paralelo con una época actual en la que el estatus social se definiría por el nivel de ingresos. La identidad basada en la vocación tiene su origen en un conjunto de normas $\mathrm{y}$ valores fuertemente influenciados por creencias y actitudes morales y religiosas, que datan de épocas en que la Iglesia gestionaba gran parte de la educación (Larrosa, 2010; Vieira y Tavares da Silveira, 2009). Luego, y desde que los Estados se han hecho cargo de la educación, el profesorado es al mismo tiempo un apóstol y un funcionario, ya que ha mantenido la legitimidad del rol público con una clara impronta vocacional (Núñez, 2004). Esto deja en una doble posición al profesorado, ya que, por un lado, para obtener reconocimiento social es necesario valorar los sistemas de incentivos de las sociedades actuales (Honnet, 2006), pero, por otro lado, muchas veces no son los incentivos los que guían su trabajo, sino el compromiso, la solidaridad, el desinterés, la justicia, la integración social y la vocación (Vidiella y Larraín, 2015).

El estudio llevado a cabo por Bedacarratx (2012) concluye al respecto que el profesorado en formación se encuentra inserto en un malestar que se relaciona con malas condiciones laborales, pero que, a la vez, convive con discursos de vocación y heroísmo que permitirían generar satisfacción en un nivel que contraste el malestar general. En este escenario, el desafío para el quehacer docente consiste en evitar pasar de la vocación a la explotación laboral con el consentimiento de quien es explotado (Seidmann, 2015). Continuar destacando en el tiempo la vocación del profesorado sin que exista un cambio en las condiciones materiales en que ésta se da, permite que el poder dominante pueda fomentar la vocación como instrumento para controlar al profesorado, además de suplir carencias materiales y formales para el desempeño profesional (Larrosa, 2010; Tenti, 2007).

A partir de lo anterior, surge la pregunta por los procesos de construcción de identidad del profesorado en el contexto público-municipal chileno, y específicamente, en sectores de pobreza. Para ello, este estudio define la identidad docente como una construcción sociohistórica, que supone la intersubjetividad y se confronta con otras identidades en el proceso de interacción social. Las diferentes imágenes que ofrecemos y recibimos generan una identidad que permite que las personas se conviertan en observadoras de sí mismas, haciendo ajustes, modificaciones o cambios (Íñiguez, 2001). En el marco de la identidad docente, estas imágenes son recibidas por parte de la comunidad educativa en el trabajo cotidiano del profesorado. De este modo, este estudio analizó la identidad docente y sus procesos de construcción intersubjetivo, a partir del relato de profesores, familias y personal de apoyo en centros educativos chilenos (municipales y de sectores de pobreza).

\section{METODOLOGÍA}

El diseño de este estudio es cualitativo (Canales, 2006). Se seleccionaron cuatro centros educativos de la Región Metropolitana y de la Quinta Región, de enseñanza básica, media, urbana y rural, cuya característica en común era poseer un Índice de Vulnerabilidad Socioeducativa (IVE) superior a $75 \%$, es decir, que atendieran a estudiantes de sectores de pobreza. A través de un muestreo abierto, relacional y discriminativo (Strauss y Corbin, 2002), se entrevistaron asistentes de la educación, autoridades educativas, estudiantes y sus familias (ver Tabla 1). Se realizó un total de 22 entrevistas individuales focalizadas (Alonso, 1998) y cuatro grupos focales (Canales, 2006). Los guiones temáticos consistieron en 
preguntas sobre el SIMCE y sus resultados; el trabajo entre el establecimiento educacional con otras instituciones o encargados de gestionar las políticas; el papel de los actores educativos responsables de implementación o resguardo de estas políticas; las formas de interactuar con la comunidad educativa y el desarrollo profesional.

Tabla 1. Participantes del estudio en vinculación con la técnica de producción de información utilizada

\begin{tabular}{|l|l|c|}
\hline $\begin{array}{l}\text { Técnica de } \\
\text { producción de } \\
\text { información }\end{array}$ & Participantes & $\begin{array}{c}\text { Número de } \\
\text { personas } \\
\text { entrevistadas }\end{array}$ \\
\hline $\begin{array}{l}\text { Entrevistas en } \\
\text { profundidad }\end{array}$ & Educadora de párvulos & 1 \\
\cline { 2 - 3 } & Coordinador comunal de Ley SEP & 1 \\
\cline { 2 - 3 } & Profesores de escuelas primarias urbanas & 6 \\
\cline { 2 - 3 } & Profesor normalista rural (primaria) & 1 \\
\cline { 2 - 3 } & Profesionales del Programa de Integración Escolar (PIE) & 4 \\
\hline \multirow{2}{*}{ Grupo focal } & Madres de escuela primaria urbana & 6 \\
\cline { 2 - 3 } & Estudiantes de escuela primaria urbana (de 5 a $8^{\circ}$ grado) & 6 \\
\cline { 2 - 3 } & Estudiantes de escuela primaria urbana (de $8^{\circ}$ grado) & 6 \\
\hline
\end{tabular}

Para el análisis de la información se realizó un análisis cualitativo de contenido a través de las fases de pre-análisis, codificación y categorización (Cáceres, 2003). El principal criterio de rigor científico fue la triangulación de credibilidad, contrastando la información con las perspectivas teóricas, con el fin de confirmar interpretaciones (Ruiz Olabuénaga, 1996). El principal resguardo ético, fue el consentimiento informado, asegurando la confidencialidad de la información (Tójar y Serrano, 2000).

\section{RESULTADOS}

En total, se construyeron dos categorías. Éstas se presentan acompañadas de respaldos de las entrevistas y grupos focales de diferentes actores de la comunidad educativa.

\subsection{LAS CONSECUENCIAS DE LA ESTANDARIZACIÓN: TECNIFICACIÓN Y MALESTAR}

Entre el profesorado, aparece el Simce como determinante de las prácticas de mejoramiento escolar. En algunos casos, este mejoramiento se asocia a una pedagogía basada en la gestión, ya que se destaca la administración de recursos como estrategia clave, vinculando mejoramiento escolar con resultados académicos. Para el profesorado, estos resultados mejorarían a través 
de un énfasis en la gestión de recursos. Asimismo, se valida que los resultados se reflejen en el Simce, aunque se perciba a esta prueba como una amenaza para las escuelas. Esta amenaza, se relaciona con el miedo al eventual cierre de las mismas como consecuencia de un mal resultado. El miedo al Simce no es tanto hacia la prueba, como hacia sus consecuencias. Paradojalmente, se teme a las consecuencias de la ley a la vez que se agradecen los recursos que ésta le entrega a las escuelas en función de los resultados de la prueba.

[...] está establecido, la Ley es, es clara que los colegios que logren los 250 puntos en el Simce hacia arriba van a continuar como colegios ¿ya? Autónomos ¿Qué pasa con los que no logran esas metas? se establece ¿cierto? que esos colegios perderían su calidad de, o su resolución, ¿cierto?, y esos chicos son distribuidos en otros colegios que tengan mejores resultados (coordinador comunal Ley SEP).

La amenaza de una escuela que tiene bajo Simce durante un cierto período de tiempo, con la inversión que ha estado en la escuela con la famosa Ley SEP, ¿si no hay resultados? Al cuarto año, la escuela desaparece. Estas son las leyes, las normas (Profesor 1 escuela primaria urbana).

Asimismo, tanto el profesorado como el estudiantado y sus familias reconocen una intensificación del trabajo en la preparación de la prueba Simce, con el fin de conseguir altos resultados. Esto, los lleva al cuestionamiento respecto de la función social de pruebas como éstas, y sus consecuencias, interpretando que este tipo de estrategias tendrían como finalidad el término de la educación pública en el país, ya que no consideran las brechas sociales derivadas de los altos índices de segregación educativa en Chile.

Hay un solo cuarto año, pero la profesora se dedicó todo el año a trabajar, prácticamente todo el año, con puro Simce, prueba Simce, ensayo Simce, que acá en la tarde, que taller en la mañana, que o sea es complicado (Profesor 2 escuela primaria urbana).

(...) por ejemplo, mi hija se siente presionada por dar la prueba Simce, están todo el día con la materia de la prueba, están todo el día (Madre, escuela primaria urbana).

Entrevistadora: ¿Pero cómo ven el Simce?

Estudiante mujer 1: ¿Cómo en qué sentido?

Estudiante mujer 2: Es como... el peor día de tu vida.

Entrevistador: ¿Por qué?

Estudiante mujer 2: Porque realmente es como un temor, falta poco pa' octubre, falta poco pa' octubre, tiene que irte bien. Es como que ojalá te pase algo. Quiero fracturarme el brazo, quiero enfermarme. ¿Por qué no me da amigdalitis justamente un día antes, que pueda darte algo? (Estudiantes $8^{\circ}$ grado escuela urbana primaria). Ahí hay también un sistema que te mide, y mide según ellos la calidad que está entregando la escuela, que a mí tampoco me parece porque a mi punto de vista lo que se está midiendo son las enormes brechas que hay entre colegios particulares y colegios municipalizados. Yo creo que apunta claramente a la política, no solamente de este gobierno, sino también de gobiernos anteriores, de terminar con la educación pública (Profesor 3 escuela primaria urbana).

En los cuestionamientos tanto del profesorado como de las familias, el Simce aparece como un instrumento al servicio de la estandarización del trabajo docente, regulando 
luego, su evaluación y profesión. En este escenario, no solo se reconoce al Simce como el instrumento orientado a aquello, sino también, a otras pruebas más propias de enseñanza secundaria, como la Prueba de Selección Universitaria (PSU), así como a otras políticas. En este contexto, la estandarización aparece como base de la tecnificación, y lo que se denuncia es el escaso margen de acción creativa y profesional que estarían dejando las políticas educativas al quehacer docente.

[...] a nosotros se nos estandariza con el Simce y con la PSU. Resulta que no todos los colegios tienen lo mismo, las mismas bases para el Simce y para la PSU, entonces la evaluación docente está estandarizada también, para todos los profesores igual (Profesora de tecnología, escuela secundaria urbana).

¿Cuándo [el profesor] trabajaba en el libro del año pasado? cuando trabajaban con clases, un libro, que era complicado. Porque ellos, los profesores, no se podían saltar clases, y si se saltaban la clase, se descompaginaba el libro (Madre, escuela primaria urbana).

La estandarización del trabajo docente aparece fortalecida con la burocratización de los tiempos y actividades escolares asociadas a las políticas actuales, las que son significadas como acciones desprovistas de sentido pedagógico e impuestas de forma arbitraria. En los discursos de las personas entrevistadas, se utiliza la metáfora de "vender una pomada" como forma de describir la sensación de estafa de programas y políticas públicas, asociada a su baja valoración y percepción de utilidad. En este sentido, se expresa una crítica vinculada con la imposición de las políticas.

[...] era una porquería más de todos los que habían llegado, porque todos los proyectos te venden una pomada, pero a ninguno le vemos un fruto, algo que digamos, sí ¿saben qué? esto nos sirvió para esto (Profesora de religión, liceo secundario urbana).

Malo porque igual es algo que te manda el Ministerio y es algo que está como dentro de una norma (Educadora de párvulos, escuela primaria urbana).

A pesar de los discursos de inconformidad frente a las acciones percibidas como imposición de parte del Mineduc, los mecanismos para rendir cuentas son interpretados por el profesorado como mecanismos que prescriben su quehacer profesional desprovisto de formas de resistencia, tecnificando de ese modo, una parte de su identidad. Dentro de estos mecanismos o instrumentos, los libros de apoyo que el Mineduc entrega al profesorado para realizar sus clases, aparecen como un mecanismo que tecnifica, ya que con los escasos tiempos que el profesorado tiene para planificar, terminan usando los libros como si se tratara de manuales, lamentando tener poas posibilidades para planificar clases creativamente.

[Refiriéndose a su antiguo trabajo en un colegio particular subvencionado] Para mí era solamente un libro de apoyo, en donde yo veía la clase, pero yo buscaba distintas maneras de hacer la clase y después esa lectura o ese trabajo del libro era de apoyo a todo lo que se había visto antes. Acá en el caso del municipal, es totalmente al revés, se trabaja a partir del libro, entonces uno escribe el objetivo en la pizarra de lo que va a trabajar en el día y después se guía en el libro solamente (Profesora de apoyo, escuela primaria urbana). 
La tecnificación se ve reflejada en el hecho de que el profesorado -y las familiasconsideran que gran parte del trabajo docente consiste en implementar estándares que han sido diseñados al margen de ellos. A esta tecnificación, se le suma la percepción de un bajo reconocimiento público sobre la labor del profesorado. Las personas entrevistadas señalan que existen una baja valoración del trabajo pedagógico expresado en bajos salarios y una sobre responsabilización en los resultados de aprendizaje. Esto mismo, es interpretado por las familias como una intensificación del trabajo docente. Las familias le agregan elementos al análisis, asociando la burocratización y poco sentido del trabajo docente, a la dificultad de un trabajo en conjunto, analizando, además, los eventuales efectos que estas condiciones podrían tener sobre el estudiantado. Finalmente, los estudiantes acusan una emocionalidad negativa en el profesorado, lo que definen como "estrés y agobio docente".

[Refiriéndose al gobierno] No quieren reconocer que el trabajo administrativo a ellos les importa más que el trabajo de aprendizaje, tampoco quieren reconocer que es importante que haya un gasto de plata del Estado en educación. No quieren reconocer que tienen que pagarnos más a los profesores. Entonces, es re fácil culpar a los profes de que los chiquillos no aprendan, pero parte del gobierno, de no ponerle el acento que corresponde a la educación (Profesora de inglés 2, liceo secundario urbana).

Yo pienso que igual el descontento, a lo mejor es que no solamente en este colegio, es generalizado. A los profesores los evalúan mucho, los fiscalizan mucho, aparte de que les pagan poco, y eso también genera un descontento, y eso sí, se quiera o no se quiera, repercute en los alumnos, que ellos están tan concentrados que tienen que pasar la materia, que tienen que estar al día, que tienen que estar aquí, y al final no se trabaja en conjunto (Madre, escuela primaria urbana).

Bueno, es que aquí es fácil ver el estrés. Nosotros vemos a la profesora, que hasta ella tiene estrés, está cansada, agobiada (Estudiante $8^{\circ}$ grado, escuela primaria urbana).

En este sentido, algunos profesores y profesoras de secundaria constatan la intensificación del trabajo docente, pero ofrecen elementos para superar el malestar. Para este grupo de docentes, la tecnificación de las políticas educativas debe enfrentarse en la organización colectiva, la que debiese transitar entre la lucha por las condiciones de trabajo y la apropiación crítica del currículum, orientándose hacia el cuestionamiento de las interacciones sociales en la escuela.

Las condiciones laborales, yo creo que los temas más sentidos hoy día es el agobio y la desprotección que tenemos los docentes en cada uno de los espacios de trabajo (Profesora de historia 4, liceo secundario urbano).

Es por eso que esta organización apuesta a fomentar y a formar a nuestros compañeros de trabajo, en que es importante la organización y que vaya más allá del aula, que nos haga cuestionarnos el currículum, que nos haga cuestionarnos la forma en que nos tenemos que relacionar con nuestros estudiantes, que nos haga cuestionar nuestras condiciones laborales y cómo eso afecta en nuestro desempeño profesional (Profesora de lenguaje 2, liceo secundario urbano).

De todos modos, todos los actores educativos coinciden en describir un ambiente de malestar docente, que se expresa a través del enojo y cansancio como estados de ánimo. 
Para algunos actores educativos, como la psicóloga que participa de un Programa de Integración Escolar, el origen del malestar docente se encuentra en las consecuencias que tendrían las políticas de rendición de cuentas como el SIMCE.

[...] los profesores quieren puro irse y eso también se ve en todos lados, si yo también creo que es por la dinámica que se está viviendo actualmente en lo que es educación, cuando el profesor llega en la mañana, dan las cuatro de la tarde, bueno las cinco de la tarde en el caso mío y lo único que queremos es irnos a la casa y no porque estemos aburridos, sino porque el contexto y el entorno ya nos tiene agotados (Profesora de apoyo, escuela primaria urbana).

[...] y ya estoy a pocos años de jubilar, ojalá fuera mañana porque cansa, ahora cansa, cansa, cansa, (Profesor de música e inglés, liceo secundario urbano).

El tema del Simce, que nos va a ir mal, que el puntaje, que no, que esto no, que no están trabajando habilidades, que tiene que trabajar así, que esto no se hace. Entonces, ellos, yo siento que igual ellos, se sienten presionados por el director, por esto de que le piden esto, entonces, como que a lo mejor es una manera de descargarse ante los niños, no sé, como de la presión que tienen por distintas partes, de que tienen que rendir, de que tienen que haber buenos resultados (Psicóloga, Programa de integración escolar, escuela primaria urbana).

En este contexto, el profesorado cuestiona la estandarización y lamenta contar con escasos espacios de empoderamiento para poder llevar a cabo un trabajo más reflexivo y creativo. Señalan además que en el actual sistema educativo municipal es muy difícil adecuar la enseñanza a las características del estudiantado y que por esto muchas veces asumen como propias las directrices del Mineduc, aunque señalan también que buscan fórmulas que les permitan avanzar en esta materia.

[...] como que no existe como una..., empoderamiento de esos espacios que nos permitan reflexionar sobre nuestro quehacer de la..., ya sea desde la misma planificación, de formar nuevos instrumentos o de buscar estrategias pa', pa' mejorar la educación (Profesora de biología y química liceo secundario urbano).

[...] las metodologías que usamos no son más allá de las tradicionales. Y manejamos el mismo currículum. O sea, tampoco estamos haciendo una innovación mayor, más allá de que en algunas asignaturas se pueda trabajar algunos conceptos un poquito más críticos o cuestionar un poquito el currículum nacional (Profesora 6, escuela primaria urbana). [...] Mucho documental, mucha noticia, mucha actualidad en cuanto a la ciencia, la tecnología. Tratar de sacarlos también al entorno, hablar de la región, porque hay que contextualizar y eso es lo más..., lo que tiene el currículum, que es tan, tan descontextualizado (Profesora 9, escuela primaria urbana).

\subsection{IDENTIDAD APOSTÓLICA Y VOCACIÓN}

En algunos discursos docentes se evidencia una mirada negativa de las familias, las que son caracterizadas como "mal constituidas", "disfuncionales" o "violentas". Esto estaría dando cuenta de un ideal normativo moral sobre el origen social de los estudiantes, pero también, de los desafíos que implica el trabajo en contextos de pobreza. 
Eso es lo que es sabido, ¿ya?, son de familias mal construidas, disfuncionales (Profesor de artes, liceo secundario urbano).

[...] vienen de familias en que a lo mejor el papá los abandonó, o la mamá los abandonó, que la mamá está pendiente en estos momentos de otra cosa (Profesora de química, liceo secundario urbano).

[...] los hombres le pegan a las mujeres, parece que en la casa es normal eso, que el papá le pega a la mamá (Profesor normalista, escuela rural primaria).

La experiencia subjetiva del profesorado entrevistado es una experiencia de desazón, que muestra que trabajar en la educación municipal conlleva complejidades que sienten que escapan de su control. La presión de rendir cuentas con resultados académicos se entremezcla con la presión de trabajar en centros educativos altamente segregados que presentan dificultades estructurales de las que finalmente se hace cargo el profesorado.

Porque ellos son los discriminados del sistema, si muchos chiquillos que están acá, y lo dicen abiertamente los apoderados, no han sido aceptados en ningún otro colegio, porque son pobres, porque tienen bajas notas, porque tienen mala conducta, porque han estado presos, porque la niña está embarazada, porque es mamá. Entonces aquí nosotros recibimos a todas esas personas que en el fondo el sistema va despreciando, y eso es lo malo, porque antiguamente la educación pública en la cual yo estudié, tú encontrabas que había un hijo de un campesino, de un obrero, y al lado de un ingeniero, un médico, y eso como que iba compensando un poco (Profesor 1 de historia, liceo secundario urbano).

El desafío que implica trabajar en contextos de vulnerabilidad social y en un país altamente desigual en educación, sitúa a la vocación en el centro del quehacer. Ésta es definida por el profesorado como una cualidad que no es valorada por las políticas: no es medida ni evaluada y tampoco tiene consecuencias positivas. De este modo, se deja ver de forma implícita un anhelo porque ésta ingrese en los mecanismos de rendición de cuentas, ya que pareciera ser un requisito fundamental del trabajo docente en contextos vulnerables que no forma parte del sistema de evaluación. Esta vocación es descrita como algo que define la identidad del profesorado en todas sus interacciones sociales y espacios de desarrollo profesional.

[...] un desafío, vulnerable, con niños con problemas, todos los días es un desafío porque no se sabe con lo que se va a encontrar (Profesora de administración de empresas, liceo secundario urbano).

En el sistema público debes tener la vocación de trabajar con estos niños y la evaluación docente no ve eso (Profesora de tecnología, liceo secundario urbano).

La vocación, el profesor tiene que usarla cuando entra a la sala, cuando sale de la sala, cuando está en el patio, cuando está en el comedor, cuando conversa con el apoderado o con el niño (Profesor normalista, escuela primaria rural).

En algunos casos el discurso de la vocación se vincula con un apostolado, asociando la docencia con sacrificio. En este contexto, y para algunos docentes, trabajar en el sector municipal implicaría sacrificar el sueldo y sus emociones, aunque esto es a la vez retribuido 
por una sensación de satisfacción personal. Sin embargo, en otros casos, la vocación es sinónimo de compromiso profesional asociado a la posibilidad de asegurar procesos de enseñanza y aprendizaje curricular.

Aquí en el fondo es como un apostolado, porque si bien uno aquí está trabajando porque le están pagando un sueldo también, pero ese sueldo que le pagan aquí no compensa para nada lo que significa el sacrificio emocional de tener que enfrentarse con estos chiquillos (Profesor de historia 1, liceo secundario urbano).

Yo entré ganando acá doscientos y tantos, ahora gano un poco más de trescientos ${ }^{2} y$ vengo re contenta a trabajar. Y llego a la casa y siento que hice una labor, y vengo al otro día contenta de nuevo. Entonces yo creo que eso es algo que ojalá los profesores pudieran rescatar: esa vocación (Profesora 2, escuela primaria urbana).

Me encanta que los niños me necesiten, entonces en ese sentido yo me siento totalmente plena en lo que hago (Profesora de lenguaje y comunicación, liceo secundario urbano). [...] veo si tiene buena letra, buena ortografía, se ciñó a las preguntas, yo le marqué lo que no correspondía. Entonces si yo le revisé eso, tengo vocación. Ponerle nota a esta prueba es re fácil [toma una prueba que estaba corrigiendo]. La tabulo. Con ocho puntos, un cuatro; con nueve puntos, un cuatro coma cinco. Pero mi vocación me dice que no es eso. Una nota no es eso. Es revisar ítem por ítem, corregir el error, revisar la ortografía. Le corrijo por qué no puso el apellido de la mamá [refiriéndose a la sección "nombre" de la prueba] y qué pasó ahí (...). Entonces eso es vocación, cuando uno hace la prueba, cuando uno hace una clase (Profesor normalista escuela primaria rural).

Finalmente, tanto en los discursos que sostienen la vocación como un sacrificio de apostolado y aquéllos que la sostienen como un compromiso profesional, es posible evidenciar contenidos altruistas y de trascendencia. El profesorado, a través de la vocación construye una identidad que se sitúa en un lugar de admiración social -como un ejemplo a seguirque atañe a la vida pública y privada. De este modo, el profesorado busca "dejar huella" y trascender, lo que se contrapone con un entorno sociocultural que estaría desacreditando la profesión docente, tal como se evidencia en el discurso de las madres entrevistadas.

[...] ese niño necesitó tu apoyo, tú lo ayudaste y el niño surgió y marcaste su vida, no sé si me entiendes (Profesora de tecnología, liceo secundario urbano).

[...] uno es ejemplo en todas partes. Los niños te miran y tú puedes marcarlos, o sea dejarles huellas positivas o negativas a los chiquillos (Profesora de química, liceo secundario urbano).

Madre 1: Los profesores eran una autoridad y ahora se le ha quitado la autoridad al docente, ahora el profesor es evaluado, está constantemente...

Madre 2: es un trabajador cualquiera dentro del colegio.

Madre 1: porque es tanto que los califican, y es tanto que ya llegan a un punto que están así como muy presionados, llegan a realizar la clase porque la tienen que hacer. O sea, ahora hay una diferencia entre los antiguos, antes eran los maestros, ahora son profesores (Madres, escuela primaria urbana).

En Chile, el salario mínimo es de USD 420 aproximadamente. Por lo que señala, la profesora percibe una remuneración mensual, levemente por encima de este monto. 


\section{DISCUSIONES}

A partir de los resultados del estudio se puede concluir que los procesos de rendición de cuentas más que favorecer la autonomía del profesorado y de los centros educativos, generan una relación de dependencia hacia la política educativa a través de sistemas complejos de estandarización de la práctica docente. La estandarización en educación que imponen las políticas se puede evidenciar en mecanismos como la prueba Simce y la evaluación docente y actúa sobre la identidad del profesorado ya que busca tecnificarlo cada vez que se espera que éste desarrolle su práctica pedagógica con estos estándares como metas. La rutinización y burocratización de actividades docentes es una expresión de diferentes formas de tecnificación (Cornejo y Reyes, 2008; Núñez, 2004; Reyes et al., 2014). De este modo, se evidencia en las entrevistas que las políticas educativas son construidas como estructuras que ofrecen identidades técnicas, con consecuencias como malestar y agobio docente (Cornejo y Reyes, 2008; Reyes et al., 2014).

¿Cómo actúan los mecanismos de estandarización que proponen esta tecnificación del rol docente? Las entrevistas señalan al Simce como uno de los principales responsables de la estandarización de las prácticas a través de la gestión de recursos como tarea primordial escolar y la amenaza de cierre de escuelas, lo que instala el miedo como sensación en el profesorado. El énfasis en la gestión, junto con la visibilización de mecanismos orientados a destacar la predominancia del mercado en las decisiones escolares, es expresión de una educación basada en el enfoque de la NGP (Verger y Normand, 2015), mientras que el miedo derivado de las sanciones y consecuencias de los resultados del Simce es parte de un accountability performativo en el marco de una prueba estandarizada con altas consecuencias (Hursh, 2008).

Frente a esta propuesta de identidad, el profesorado responde con una identidad que no solo se ha construido como forma de enfrentar las consecuencias de agobio y malestar, sino que obedece al legado histórico del magisterio. La identidad apostólica, que conlleva diferentes formas de vocación paradojales -como asistencialismo, autoexplotación y compromiso profesional al mismo tiempo- se basa en la historia del profesorado chileno, pero también, es expresión de mecanismos que le permiten al docente recuperar el reconocimiento social perdido (Larrosa, 2010; Núñez, 2004; Vieira y Tavares da Silveira, 2009). Este reconocimiento se habría perdido por los cambios históricos de la nación, pero al menos desde la perspectiva de las madres entrevistadas, la tecnificación docente que se evidencia en el exceso de evaluaciones y rendición de cuentas al cual se ve sometido el profesorado, sería una forma de sometimiento del docente que le resta reconocimiento público y estima social. Desde algunos docentes y estas madres, los salarios del profesorado y las condiciones en las que llevan a cabo su labor son síntomas de un paulatino descrédito de la profesión docente (Fernández, 2001; Gavilán, 1999) que se enfrenta con el sentido de relevancia y trascendencia que otros profesores asocian a su trabajo.

El juicio social negativo sobre el profesorado (Esteve, 2009; Guerrero, 2017) sería una expresión más del escenario en el que se desarrolla su labor: el accountability en un país altamente segregado, y, por lo tanto, que ha equiparado a la educación municipal a educación en contexto de pobreza. El estudio de Falabella (2015) concuerda con estos hallazgos, cuando señala que el profesorado de estos sectores trabaja en establecimientos con reputación negativa y con altos niveles de frustración, lo que en parte sería expresión del choque entre la política y las subjetividades y prácticas cotidianas escolares. 
Si bien la identidad del profesorado no responde exclusivamente a la propuesta identitaria que realizan las políticas de rendición de cuentas, y no es posible determinar que los significados expresados por las personas entrevistadas sean una consecuencia directa - $\mathrm{O}$ exclusiva- de las políticas de accountability, sí constituyen el marco en el cual se construye esta identidad. Estas políticas son descritas por el profesorado como restrictivas de la autonomía docente, lo que ocurre fundamentalmente en un contexto que es identificado por ellos mismos como desigual (Cavieres, 2014). En dicho sentido, este estudio coincide con los resultados publicados por Falabella (2015) respecto de las tensiones en establecimientos de sectores de pobreza, los que enfrentan desafíos impredecibles y enfatizan la formación social y emocional. Este contexto laboral y profesional, combinado con las presiones por obtener altos resultados, deteriora los ambientes de trabajo (Reyes et al., 2010) y prioriza las racionalidades instrumentales (Falabella, 2015). Frente a esto, algunos docentes construyen un discurso de enfrentamiento a la intensificación y desprofesionalización del trabajo, analizando ambos fenómenos como una situación de injusticia social, y apostando por la acción organizada como mecanismo de resistencia. Esta idea ya había sido introducida por Hargreaves (2003), instando al profesorado a construir comunidades de aprendizajes en el actual contexto de estandarización.

Asimismo, aparece un doble sentido de la vocación como se mencionó en los párrafos anteriores. Este doble sentido le permite al profesorado autovalorarse y reafirmar su compromiso profesional en contextos de pobreza (Falabella, 2015), pero al mismo tiempo, permite la internalización de la dominación en cuanto convierte la intensificación laboral en autointensificación (Honnet, 2006) dando cuenta del papel subjetivante de las políticas educativas (Fardella y Sisto, 2015; Sisto, 2012).

A partir de este estudio, surge la pregunta por el lugar del currículum y de la acción cotidiana en el aula, así como por la percepción -de un modo más profundodel estudiantado y las familias respecto del rol docente y de las políticas educativas. Finalmente, una limitación de este estudio es el restringido número de entrevistas y de colegios con los que se trabajó, lo que no permite distinguir con claridad diferencias entre tipos de establecimientos educativos, ni entre estamentos para dar cuenta de los procesos identitarios.

\section{REFERENCIAS BIBLIOGRÁFICAS}

Alfonso, A. (2016). El campo de las políticas de evaluación y accountability en educación: para una reflexión más densa. Profesorado. Revista de currículum y formación del profesorado, 20(3) $1-12$.

Almonacid, C. (2001). La creación de mercados educacionales en Chile. Cuadernos de Pedagogía, 308, 65-70.

Almonacid, C; Luzón, A. y Torres, M. (2009). Cuasi mercado educacional en Chile: el discurso de los tomadores de decisión. Education Policy Analysis Archives/Archivos Analíticos de Políticas Educativas, 16(8) 1-47.

Alonso, L. (1998). La mirada cualitativa en sociología. Madrid: Fundamentos.

Alves, F.; Elacqua, G.; Koslinki, M.; Martínez, M.; Santos, H.; Urbina, D. y Aguilera, N. (2015). Una revolución neoliberal: la política educacional en Chile desde la dictadura militar. Educação e Pesquisa, 41 (spe), 1473-1486.

Assáel, J. y Pavez, J. (2008). La construcción e implementación del sistema de evaluación del 
desempeño docente chileno: principales tensiones y desafíos. Revista Iberoamericana de Evaluación Educativa, 1(2), 42-55.

Ávalos, B., y Sotomayor, C. (2012). Cómo ven su identidad los docentes chilenos. Perspectiva Educacional, Formación de Profesores, 51(1), 57-86.

Bazán, D., y González, L. (2007). Autonomía profesional y reflexión del docente: una resignificación desde la mirada crítica. REXE. Revista de Estudios y Experiencias en Educación, (11), 69-90.

Bedacarratx, V.A., (2012). Futuros maestros y construcción de una identidad profesional: una mirada psicosocial a los procesos que se ponen en juego en los trayectos de formación en la práctica. Revista Electrónica de Investigación Educativa, 14(2), 133-149.

Bellei, C. (2013). El estudio de la segregación socioeconómica y académica de la educación chilena. Estudios Pedagógicos (Valdivia), 39(1) 325-345.

Beltrán, J. (2016). Medida y valor de la escuela. Desde la rendición de cuentas hasta la rendición de sentido. Profesorado, revista de currículum y formación del profesorado, 20(3), 119-143.

Biscarra, C., Giaconi, C. y Assáel, J. (2015). El docente en la legislación educacional chilena. Psicoperspectivas, Individuo y Sociedad, 14(3), 80-92.

Bolívar, A. (2005). ¿Dónde situar los esfuerzos de mejora?: Política educativa, escuela y aula. Educação e Sociedade, 26(92), 859-888.

Bolívar, A. (2010). La Lógica del Compromiso del Profesorado y la Responsabilidad del Centro Escolar. Una Revisión Actual. REICE. Revista Iberoamericana sobre Calidad, Eficacia y Cambio en Educación, 8(2), 10-33.

Brooke, N. (2016) High-stakes accountability using teacher salary incentives in Brazil: An update. Profesorado, revista de currículum y formación del profesorado, 20(3) 207-250.

Cáceres, P. (2003). Análisis cualitativo de contenido: una alternativa metodológica alcanzable. Psicoperspectivas, Individuo y Sociedad, 2(1), 53-82.

Canales, M (2006). Metodologías de la investigación social: Introducción a los oficios. Santiago, Chile: Lom.

Carrasco, C; Ascorra, P., López, V. y Álvarez, J.P (2018). Tensiones normativas de los fiscalizadores de la Superintendencia de Educación en la(s) política(s) de convivencia escolar en Chile. Perfiles Educativos, 40(159), 126-143.

Cavieres, E. (2014). La calidad de la educación como parte del problema Educación escolar y desigualdad en Chile. Revista Brasileira de Educação. 19(59), 1033-1051.

Cavieres, E. y Apple, M. (2016). La ley docente y la clase media: controlando el desarrollo de los profesores chilenos. Cuadernos CEDES, 36(100), 265-280.

Cornejo, R. y Reyes, L. (2008). La cuestión docente Chile: experiencias organizacionales y acción colectiva de profesores. Buenos Aires: Fund. Laboratorio de Políticas Públicas. Foro Latinoamericano de Políticas Educativas - FLAPE.

Cornejo, R., Albornoz, N. Castañeda, L., Palacios, D. Etcheberrigaray, G., Fernández, R., Gómez, S., Hidalgo, F. \& Lagos, J. I. (2015). Las prescripciones del trabajo docente en el nuevo marco regulatorio de políticas educativas en Chile. Psicoperspectivas, Individuo y Sociedad, 14(2), $72-83$.

De la Vega, L. (2015). Accountabilty y Mejoramiento Educativo: análisis de experiencias internacionales. Educação \& Realidade, 40(1), 275-298.

Dussaillant, F. y Guzmán, E. (2014). ¿Por qué Finlandia puede prescindir de accountability formal en educación y Polonia no? Calidad en la educación, (41), 137-158.

Dutercq, Y. (2016). Accountability, una caja de herramientas, no una política: El caso del sistema educativo francés. Profesorado, revista de currículum y formación del profesorado, 20(3), 145169.

Elacqua, G. y Santos, H. (2013). Preferencias reveladas de los proveedores de educación privada en Chile: El caso de la Ley de Subvención Escolar Preferencial. Gestión y política pública, 22(1), 85-129. 
Esteve, J. (2009). La profesión docente ante los desafíos de la sociedad del conocimiento. En C. Vélaz de Medrano \& D. Vaillant (Ed.) (pp. 17-27) Aprendizaje y desarrollo profesional docente. Madrid: Santillana.

Etcheberrigaray, G., Lagos, J., Cornejo, R., Albornoz, N. y Fernández, R. (2017). Concepciones sobre docencia en el nuevo marco regulatorio del sistema escolar chileno. Revista de psicología, 26(1), 1-13.

Falabella, A. y De la Vega, L. (2016). Políticas de responsabilización por desempeño escolar: Un debate a partir de la literatura internacional y el caso chileno. Estudios Pedagógicos (Valdivia), 42(2), 395-413.

Falabella, A. (2018). La seducción por el Estado supervigilante en la educación escolar chilena: Un recorrido de 1979 a 2011. En C. Ruiz, F. Herrera y L. Reyes (Eds.). Educación Pública y Privatización. Santiago: Editorial Universitaria.

. (2015). El mercado escolar en Chile y el surgimiento de la nueva gestión pública: el tejido de la política entre la dictadura neoliberal y los gobiernos de la centroizquierda (1979 a 2009). Educação \& Sociedade, 36(132), 699-722.

Fardella, C. y Sisto, V. (2015). Nuevas regulaciones del trabajo docente en Chile. Discurso, subjetividad y resistencia. Psicologia \& Sociedade, 27(1), 68-79.

Fardella, C. (2013). Resistencias cotidianas en torno a la institucionalización del modelo neoliberal en las políticas educacionales: El caso de la docencia en Chile. Psicoperspectivas, Individuo y Sociedad, 12(2), 83-92.

Fernández, M. (2001). A la busca de un modelo profesional para la docencia ¿liberal, burocrático o democrático? Revista Iberoamericana de Educación, (25), 43- 64.

Flórez, M.T. (2015). Validity and equity in educational measurement: The case of Simce. Psicoperspectivas, Individuo y Sociedad, 14(3), 31-44.

Galaz, A. (2011). El profesor y su identidad profesional. ¿Facilitadores u obstáculos del cambio educativo? Estudios Pedagógicos (Valdivia), 37(2), 89-107.

(2015). Evaluación e identidad profesional del profesor. ¿Un juego de espejos rotos? Andamios, 12(27), 305-333.

Gavilán, M. (1999). La desvaloración del rol docente. Revista Iberoamericana de Educación, (19), 211-228.

Giroux, H. (1992). Teoría y resistencia en educación. México: Siglo XXI.

González, J. C. (2002). La construcción de los "otros" en la cultura educativa: análisis de algunos discursos sociales y políticos sobre el docente. Education in the knowledge society, 3.

Guerrero, P. (2017). Equidad, justicia y reconocimiento en el trabajo de los profesores/as de las escuelas vulnerables chilenas. Trabalho (En) Cena, 2(2) 98-113.

Hargreaves, A. (2003). La educación en la era de la inventiva. Barcelona: Octaedro.

Heilig, J. V., y Darling-Hammond, L. (2008). Accountability Texas-style: The progress and learning of urban minority students in a high-stakes testing context. Educational Evaluation and Policy Analysis, 30(2), 75-110.

Honneth, A. (2006). El reconocimiento como ideología. Isegoría (35), 129-150.

Hursh, D. (2008) High-Stake Testing and the decline of teaching and learning. The real crisis in education. Maryland: Rowman \& Littlefield Publishers, Inc.

Hypolito, A., Pizzi, L. y Vieira, J. (2009). Reestructuração curricular e auto-intensifição do trabalho docente. Currículo sem Fronteiras, 9(2), 100-112.

Insunza, J.; Assáel, J. y Scherping, G. (2011) Formación docente inicial y en servicio en Chile: tensiones de un modelo neoliberal. RMIE, 16(48), 267-292.

Íñiguez, L. (2001). Identidad de lo personal a lo social. Un recorrido conceptual. En E. Crespo, (Ed.) La constitución social de la subjetividad. Madrid: Catarata.

Joiko, S. (2012). El cuasi-mercado educativo en Chile: Desarrollo y consecuencias, Revista electrónica Diálogos Educativos, 12(23), 148-174. 
Kallo, J. (2009). OECD Education Policy. A comparative and historical study focusing on the thematic reviews of tertiary education. Helsinki: FERA.

Larrosa, F. (2010). Vocación docente versus profesión docente en las organizaciones educativas. Revista Electrónica Interuniversitaria de Formación del Profesorado, 13(4), 43-51.

Lima, L. (2016). Evaluación hiperburocrática. Profesorado, revista de currículum y formación del profesorado, 20(3), 87-118.

López, V. (2014). Convivencia Escolar. Apuntes. Educación y Desarrollo Post-2015-UNESCO. 4, 1-18 Recuperado en 5 octubre 2017 desde http://www.unesco.org/new/fileadmin/MULTIMEDIA/ FIELD/Santiago/pdf/APUNTE04-ESP.pdf.

Luzón, A. y Torres, M. (2013). Apuntes sobre la internacionalización y la globalización en educación: de la internacionalización de los modelos educativos a un nuevo modelo de gobernanza. Journal of Supranational Policies of Education, (1), 53-66.

McMeekin, R. (2006). Acreditación, accountability y mejoramiento de la calidad de la educación en escuelas vulnerables. Revista Pensamiento Educativo, 39(2), 237-253.

Mediavilla, M.; Zancajo, A.; Verger, A. y Bonal, X. (2013). Chile y su política de cuasi-mercado para la elección de centro. Un análisis a partir del SIMCE 2011. Ponencia presentada en las XXII Jornadas de la Asociación de Economía de la Educación en A Coruña, España, 4 y 5 de julio de 2013 Disponibles en http://2013.economicsofeducation.com/user/programa2.php?lang=es.

Núñez, I. (2004). La identidad de los docentes una mirada histórica. Santiago: PIIE.

Parcerisa, L., y Falabella, A. (2017). La consolidación del Estado evaluador a través de políticas de rendición de cuentas: Trayectoria, producción y tensiones en el sistema educativo chileno. Education Policy Analysis Archives, 25(89), 1-27.

Parcerisa, L. y Verger, A. (2016). Rendición de cuentas y política educativa: Una revisión de la evidencia internacional y futuros retos para la investigación Profesorado. Revista de Currículum y Formación de Profesorado, 20(3), 15-51.

Pino, M., Oyarzún, G., \& Salinas, I. (2016). Crítica a la estandarización para la rendición de cuentas: narrativas de resistencia para transformar el sistema de evaluación en Chile, Cadernos Cedes, 36(100), 337-354.

Popkewitz, T. (2009). El cosmopolitismo y la era de la reforma escolar: la ciencia, la educación y la construcción de sociedad mediante la construcción de la infancia. Madrid: Morata.

Ravitch, D. (2010). The myth of charter schools. The New York Review of Books (Noviembre, 11) Recuperado de http://www.nybooks.com/articles/2010/11/11/myth-charter-schools/.

Reyes, L., Cornejo, R., Arévalo, A., y Sánchez, R. (2010). Ser docente y subjetividad histórica en el Chile actual: discursos, prácticas y resistencias. Polis. Revista Latinoamericana, (27).

Reyes, L. y Pino, M. (2010). Desprofissionalização docente. En D. A. Oliveira, A.M.C. Duarte y L.M.F. Vieira (Comp.), Dicionário: Trabalho, profissão e condição docente. Belo Horizonte: UFMG/Faculdade de Educação.

Reyes, T.; Varas, Al. y Zelaya, V. (2014). Sobre la construcción de la enfermedad en el discurso del malestar docente, Revista de Psicología (Universidad de Chile), 23(2), 88-100.

Rojas, M. y Leyton, D. (2014). La nueva subjetividad docente. Construcción de subjetividades docentes en los inicios de la implementación de la Subvención Escolar Preferencial en Chile. Estudios Pedagógicos (Valdivia), 40(Especial), 205-221.

Ruiz Olabuénaga, J.I. (1996). Metodología de la investigación cualitativa. Bilbao: Universidad de Deusto.

Schildkamp, K., y Ehren, M. (2013). From "intuition" to "data" based decision making in dutch secondary schools? In data-based decision making in education (pp. 49-67). Springer Netherlands.

Seidmann, S. (2015). Identidad personal y subjetividad social: educación y constitución subjetiva. Cadernos de pesquisa, 45(156), 344-357.

Sisto, V., y Fardella, C. (2011). Nuevas políticas públicas, epocalismo e Identidad: El caso de las 
políticas orientadas a los docentes en Chile. Reu, Sorocaba, SP, 37(1), 123-141.

Sisto, V. (2011). Nuevo profesionalismo y profesores: Una reflexión a partir del análisis de las actuales políticas de 'profesionalización' para la educación en Chile. Revista Signo y Pensamiento, 31(59), 178-192.

. (2012). Identidades desafiadas: Individualización, managerialismo y trabajo docente en el Chile actual. Psykhe, 21(2), 35-46.

Strauss, A., y Corbin, J. (2002). Bases de la investigación cualitativa. Técnicas y procedimientos para desarrollar la teoría fundamentada. Antioquía: Contus, Universidad de Antioquía.

Tenti, E. (2007). Consideraciones sociológicas sobre Profesionalización Docente. Educ. Soc., Campinas, 28(99), 335-353.

Tójar, J.C. y Serrano, J. (2000). Ética e investigación educativa. Relieve, 6(2).

Verger, A. y Normand, R. (2015). Nueva Gestión Pública y Educación: Elementos teóricos y conceptuales para el estudio de un modelo de reforma educativa global. Educação \& Sociedade, 36(132), 599-622.

Verger, A.; Zancajo, A. y Fontdevila, C. (2016). La economía política de la privatización educativa: políticas, tendencias y trayectorias desde una perspectiva comparada. Revista Colombiana de Educación, (70), 47-48.

Vidiella, J. y Larraín, V. (2015). El papel de las condiciones de trabajo en la construcción de la identidad docente: Corporalidades, afectos y saberes. Revista mexicana de investigación educativa, 20(67), 1281-1310.

Vieira, M. y Tavares da Silveira, P. (2009). Identidade Docente em Tempos de Educação a Distância. Fundamentos en Humanidades. Universidad Nacional de San Luis, 10(2), 201- 219.

Villalobos, C. y Quaresma, M. (2015). Sistema escolar chileno: características y consecuencias de un modelo orientado al mercado. Convergencia, 22(69), 63-84.

Wayman, J. C., Spikes, D. D. y Volonnino, M. R. (2013). Implementation of a Data Initiative in the NCLB Era. En: Schildkamp, K.; Lai, M.; Earl, L. (Eds.). Data-based Decision Making in Education (pp. 135-153) Dordrecht: Springer. 
